\title{
Resisting to Game of Thrones: a fannish agonism
}

Resisting to Game of Thrones

\section{Thiago Ianatoni Camargo, André Luiz Maranhão de Souza-Leão and Bruno Melo Moura \\ Administration Graduate Program, Universidade Federal de Pernambuco, Recife, Brazil}

\begin{abstract}
Purpose - Fans have been characterized as specialized consumers who often express disagreements with the entertainment industry's decisions, especially when it comes to the original content of the works that serve as the basis for the development of media products, evidencing a kind of consumer resistance. Under a Foucauldian perspective aligned with the consumer culture theory (CCT), power relations are established in a dynamic of power exercise and resistance to power. Based on this, the authors pose the following research question: how do fans of media products resist the changes made by the entertainment industry in relation to their canons?

Design/methodology/approach - The authors adopted the Foucault's genealogy of power as a method, analyzing the comments posted on the Westeros.Org website, the main discussion forum of fans of A Song of Ice and Fire (ASolaF) book series and Game of Thrones (GoT) TV series.

Findings - The findings reveal ways of resistance in relation to the adaptation of the media text permeated by an entertainment dispositif, which considers the adaptation legitimate, and a fannish dispositif, which criticizes the way this adaptation was made. However, their empirical categories reveal that they are forged not only from singularities but also from overlaps. The authors conclude, therefore, that this process occurs in an agonist way, in which conflicts are fought as a reciprocal incitement revealing a productive and ethical relationship.

Originality/value - The agonism shows how consumers can simultaneously be led to incorporate and resist to discourses and market practices. This demonstrates how resistance is not necessarily a force opposed to another, but a dynamic of reciprocal negotiation.
\end{abstract}

Keywords Game of thrones, Resistance, Genealogy, Foucault, Consumer culture theory

Paper type Research paper

\section{Introduction}

Fans has been characterized as specialized consumers (de Souza-Leão \& Moura, 2018; Lanier Jr, Rader \& Fowler III, 2015). When they get together to discuss popular culture products, they express a way of marginal cultural creation, through a voice that responds to texts, producers and the entertainment industry (Hackley \& Hackley, 2018; Jenkins, 2015). These discussions often manifest positions of disagreement as to the elements that permeate their fannish (e.g. content presented in the cultural object, interactions in the fandoms and position of the entertainment industry) (Chen, 2021; Hewer, Gannon \& Cordina, 2017).

(C) Thiago Ianatoni Camargo, André Luiz Maranhão de Souza-Leão and Bruno Melo Moura. Published in Revista de Gestão. Published by Emerald Publishing Limited. This article is published under the Creative Commons Attribution (CC BY 4.0) licence. Anyone may reproduce, distribute, translate and create derivative works of this article (for both commercial and non-commercial purposes), subject to full attribution to the original publication and authors. The full terms of this licence may be seen at http:// creativecommons.org/licences/by/4.0/legalcode

The National Council for Scientific and Technological Development (CNPq) supported the research.

The Coordination for the Improvement of Higher Education Personnel (CAPES) supports the graduate program to which researchers are affiliated.

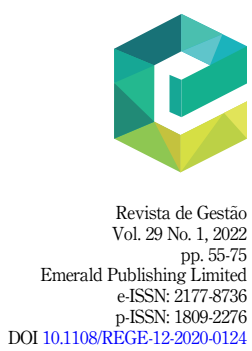


REGE

29,1

Among the most common positions of disagreement between fans, stands out the search for preserving the original content of the works that serve as the basis for the development of media products, such as books or comic books that give rise to cinematographic and television series or video games. These original contents are assumed to be canonical, and fans often understand that they are produced or distributed by the entertainment industry in inaccurate ways (Goodman, 2015; Myers, 2017).

This situation occurs in a market context, which can be understood as an arena of sociocultural interaction, where different power forces coexist (Bhattacharjee, Berger \& Menon, 2014; Denegri-Knott \& Tadajewski, 2017). In fan interactions, it is possible to analyze such power relations in the way fans establish their communities (i.e. fandoms), since hierarchies among members are identifiable (Hewer et al., 2017; Kozinets, 2001). Then, it is clear how power relationships can regulate this social experience (Arnould \& Thompson, 2015). This is because power relations between fans usually characterize the very existence of fan culture, since these consumers may or may not align their practices and positions with the discourses with both the entertainment industry and other fans (Chen, 2021; De Certeau, 1984).

Among the theoretical perspectives on power that support research in the emerging consumer culture theory (CCT) field, the approach developed by Michel Foucault has stood out (Denegri-Knott \& Tadajewski, 2017; Mikkonen \& Bajde, 2013). Studies in this theoretical field consider the market as an agent that exercises power over others (Harju \& Huovinen, 2015; Parmentier \& Fischer, 2015), since it regulates and directs how knowledge, practices and institutions relate and impact, directly or indirectly, the practices of consumers (BokekCohen, 2016; Karababa \& Ger, 2011; Zajc, 2015).

According to Foucault (2014a, b), power is not something that can be owned and used by someone over someone else; it is exercised through practices and relationships that affect the individuals, separating, differentiating, organizing and regulating their conduct. From this perspective, power escapes the idea of domination and is defined as a possibility of articulation and negotiation in the way individuals are governed. For this to happen, resistance to power is a sine qua non condition, otherwise it would not refer to power, but to domination.

Resistance and the exercise of power belong to the same field of possibilities, distinguished only by their directions, intensities and the way they are performed. The notion of resistance, therefore, refers to the possibility of modifying the effects of power (Foucault, 2008, 2014b). From this point of view, power and resistance emerge amid a distinct and strategically organized set of discursive (e.g. knowledge, texts) and nondiscursive (e.g. rules, laws, fields of knowledge, institutions) elements, which can be named as dispositifs of power. These dispositifs comprise the necessary conditions in which the practices of power and resistance that sustain or modify social reality emerge (Foucault, 2014a, b).

Thus, it is possible to conceive that opinions and behaviors produced in fandom interactions that are contrary to the directions that the entertainment industry defines for certain media products express an exercise of resistance. Based on this, we pose the following research question: how do fans of media products resist the changes made by the entertainment industry on their canons? With this referral, we focus on the consumer resistance to new logics of cultural distribution (Bokek-Cohen, 2016; Coskuner-Balli, 2020), putting light on the subculture of fans and its practices, an interdisciplinary theme that has been gaining ground in consumer culture research (Fuschillo, 2016; Zajc, 2015). For this purpose, Michel Foucault's theory provides a fruitful ground to reflect on the conditions that support the tensions and forms of power operation in market contexts (Arnould \& Thompson, 2015).

To carry out this research, we investigate Westeros.org, a forum of A Song of Ice and Fire (ASoIaF) fans. It is a book series written by George R. R. Martin (GRRM), a former Hollywood 
screenwriter, and the inspiration to Game of Thrones (GoT), a TV series that became a popular culture phenomenon broadcasted between 2011 and 2019 on the Home Box Office (HBO) channel network (MacNeill, 2017; Rappas, 2019). Throughout the 2010s, the show had unprecedented achievements regarding production investment, audience records, awards and the sale of licensed products, indicating its economic relevance for the entertainment industry (Clark, 2019; Maas, 2019; Spanò, 2016).

Some of its numbers are impressive: the countries that invested to host the series' locations (i.e. Croatia, Northern Ireland, the United Kingdom), received up to ten times more in visits from tourists (McElroy \& Noonan, 2019; Ramsey, Baker \& Porter, 2019). In the United States, the world's largest television consumer market, it had an increasing average audience over the seasons: from 9.3 million in 2011, it jumped to 32.8 million in 2019. The series also became a huge critic recognition, receiving 738 nominations and winning 269, 59 of them Primetime Emmy Award, the most important television award (Mathews, 2018; Feldman, 2019).

Culturally, HBO's production reached the status of the most pirated series in the world (MacNeill, 2017; Steiner, 2015), in addition to encouraging its audience to watch the show simultaneously with the release to avoid knowing the content through interactions on the web (i.e. spoilers) (Sarikakis, Krug \& Rodriguez-Amat, 2017): of the 207 countries in which it was broadcast, 194 of them presented the option to their consumers to watch the content following the American launch time (Feldman, 2019). Still, the series is considered a media phenomenon that promoted discussions on identity and political agendas (e.g. gender, race) (Clapton \& Shepherd, 2016; Perks \& McElrath-Hart, 2016). However, as relationships between fans are not always peaceful (Hewer et al., 2017), Westeros.org does not escape this. The interactions between fans evidence power relationships on the individual volume of content production and expertise about the fictional universe. However, it happens specially among fans who stand for or against the direction taken by the plot of the television show compared do the book series (Sarikakis et al., 2017), what became even more striking along the final seasons and mainly after the ending of the show (Ellis, 2019). This fans movement is due to how, from the fifth season, GoT started to present a different narrative of ASoIaF, since the final books of the saga have not yet been published (George, 2018; Spanò, 2016). Narrative differences have become one of the main topics discussed among fans, leading even part of the fandom to organize a movement against the lack of canonical fidelity of the TV adaptation (Ellis, 2019).

As practical implications, our study aligns with those seeking to exploit with consumer resistance not limited to the marketplace (see Denegri-Knott \& Tadajewski, 2017; Lee, Roux, Cherrier \& Cova, 2011), but focusing on the relationships and hierarchies that they are commonly established among fans (see Hewer et al., 2017; Fuschillo, 2020). It also seeks to reflect on how decisions made by producers in the entertainment industry tend to produce fan movements that expose the resonance of the cultural objects they consume whether they are aligned with their interests or not (see Chen, 2021; Parmentier \& Fischer, 2015).

\section{The participative productivity of fans}

The entertainment industry counts with a singular, specialized type of consumers: the fans. They used to act in a participatory way to influence the perception of others about their consumption (Booth, 2018; De Certeau, 1984). This can be seen in the way they commonly seek to establish fan practices and social relationships with other fans and with the cultural object in order to legitimize the level of their involvement with what they do (Fuschillo, 2020; Jenkins, 2015). Fan practices lead them to assume appropriate popular culture (e.g. comics, movies, TV shows, games, music, books) narratives, signs and values, re-signifying what
Resisting to Game of Thrones 
REGE 29,1

they consume (Myers, 2017; Sarikakis et al., 2017). Fannish is characterized by the way in which fans relate to each other and to different products of popular culture (Kozinets, 2001; Lanier Jr, Rader \& Fowler III, 2015). It is common for fans to gather in communities to create content, interact and report their consumption experiences (Hackley \& Hackley, 2018; Mittel, 2015). Fan communities, as known as fandom, consist of spaces for socialization, production of culture and affirmation of lifestyles (Fuschillo, 2016; Lanier Jr, Rader \& Fowler III, 2015). They are collective spaces for the perpetuation and propagation of activities, which aim to represent and expand the meaning that the consumption of popular culture products has in the lives of fans (Booth, 2018; Guschwan, 2012). Thus, fan's practices are more than collective; they are participatory (Guschwan, 2012; Fuschillo, 2016).

According to Jenkins (2015), they are emblematic to represent how individuals appropriate the available technology to play a leading role in participatory cultures. This conception comprises a change in the way people interact, in order to move from a passive consumption posture to conduct a performance based on a proactive participation as a means of socialization (Chen, 2021; Zajc, 2015). It represents a cultural convergence that occurs both through the consumption of media texts and to reach people who feel close by sharing consumption preferences (Fuschillo, 2020; Jenkins, 2015).

With the advances in Information and Communication Technologies (ICT), participatory cultures and fandoms have migrated to virtual environment (Guschwan, 2012; Obiegbu, Larsen, Ellis \& O'Reilly, 2019). This can be seen mainly in the forms of social organization, since fandoms represent arranges demarcated by an intense cultural production (Fuschillo, 2016; Lanier Jr, Rader \& Fowler III, 2015). In this context, fans are no longer limited by physical barriers, which provide a greater possibility for interaction, expression of opinions and sharing of the content they produce (Hackley \& Hackley, 2018; Jenkins, 2015). This participatory stance comprises appropriations of signs established in the original content as a resource to produce their discourses (Ritzer, Dean \& Jurgenson, 2012), expanding the media texts to which they are linked (Chen, 2021; de Souza-Leão \& Moura, 2018).

Fan practices bring together and overlap the notions of consumption and production, characterizing fans as prosumers (de Souza-Leão \& Costa, 2018; Zajc, 2015). The prospective characteristic of fans makes them take on tasks that, originally, would be up to producers in the dual consumption-production model. This productivity leads fans to position themselves in relation to the incidence of different power exercises mediated by market logic (Boyaval \& Herbert, 2018). Consequently, they also provide a degree of freedom that is not shared by other consumers, since they resist exercises of power through their productivity (Chen, 2021; de Souza-Leão \& Costa, 2018).

Overviewing the article structure, in terms of theoretical foundation, it is organized in three parts: first we postulate the fan interactions as productive practices; then we expand this argument to the understanding of consumer relationships conceived as market resistance; this allows us to access Foucault's concepts of resistance and power exercise. Methodological procedures are in line with this theoretical lens, through the adoption of Foucault's genealogy of power. The results are presented first as analytical description and then are interpreted through returning to theory, highlighting an agonistic stance identified in the analysis. Finally, we lay on concluding remarks.

\section{Resistance through market relations}

Marketing research has long sought to identify the conditions that guide the way in which individuals resist consumption (Mikkonen \& Bajde, 2013; Thompson, Arnould \& Giesler, 2013). For the CCT field, market cultures have established themselves as spaces of power relations, in which it is possible for different market agents to mutually 
modify themselves through positions and actions. These are practices that indicate resistance to conduct established by market logic (Denegri-Knott \& Tadajewski, 2017; Lee, et al., 2011).

The notion of resistance used by studies that deal with consumption as a cultural practice is linked to the perception that there is a result of negotiations between different market agents. Amid networks of power relations, the market allows consumers and producers to position themselves to achieve their interests (de Oliveira, Chevitarese \& Ayrosa, 2019; Mikkonen, Moisander \& Firat, 2011). In this understanding, the market is a possible way for people to resist the domination of forces that seek to govern them (e.g. boycotts of brands and products, maximizing the usefulness of goods, defending the sovereignty of consumer choice) through their relations of consumption (Bhattacharjee, et al., 2014; Denegri-Knott \& Tadajewski, 2017).

On the one hand, this notion is supported by the idea of the consumer as an autonomous agent, who exercises choices based on a self-sufficient rationality and in attention to his/her needs and interests (Gurrieri \& Cherrier, 2013; Zanette \& Brito, 2019). Thus, power is treated as an ability to act on others, as a means of achieving their goals, with resistance being the possible way for consumers to break free from the dominance of other market agents (Harju \& Huovinen, 2015; Suarez \& Erbisti, 2019). On the other hand, the resignification of market signs by consumers is capable of manifesting subjective aspects (i.e. identities, belonging to communities) (Scaraboto \& Fischer, 2013). Here, resistance does not seek to oppose dominant market forces, but to liberate the consumer: it is a symbolic struggle that seeks to prevent the market from transforming active citizens into passive consumers (Mikkonen \& Bajde, 2013; Zajc, 2015).

Consumer resistance directly impacts the way that marketing strategies are reframed and incorporated as consumption patterns (Kedzior \& Allen, 2016) and how the positions of different market agents influence the establishment of consumer subcultures (Cronin \& Hopkinson, 2018; Lee et al., 2011). This is because the resistance carried out through market relationships allows, ultimately, the maintenance of the moral subjectivity of consumers (Coskuner-Balli, 2020; Karababa \& Ger, 2011).

Among the perceptions of resistance and the power relations that ground it, Michel Foucault's contributions have stood out as an emerging trend in CCT studies (Chen, 2021; Denegri-Knott \& Tadajewski, 2017). Some studies consider that the exercise of resistance to market contributes to the constitution and institutionalization of truths (Canniford \& Karababa, 2013; Bryce, MacLaren \& O'Gorman, 2013); others evoke the concept of Foucault's dispositif to present consumer practices as a suitable arena for establishing and subverting consumer behavior (Bokek-Cohen, 2016; Johnson, Thomas \& Grier, 2017) or organizations (Chen, 2021; Hunter, 2018). No wonder, Arnould and Thompson (2015) indicate them as a fruitful path for investigations that expand the epistemological and theoretical lenses that allow the development of CCT investigations.

\section{Resistance and power in Michel Foucault}

According to Foucault (2014b), resistance is established in the exercise of power, reflecting a possibility of reaction to its effects. Both are forces of the same order and inseparable from each other. Because they are similar forces, not opposed, but reactive, resistance is a practice oriented to intervene in the exercise of power, modifying its results and shaping the production of conduct (Foucault, 2008, 2014c).

The synergy between resistance and power prevents the exercise of power from resulting in imposing and inescapable domination. These forces constitute relationships that arise amid conditions of differentiation between people, by modifying, organizing, controlling and regulating the way they conduct themselves (Foucault, 2014b, 2014c). Consequently, power
Resisting to Game of Thrones 
REGE 29,1

and resistance make up a relational practice and are differentiated by their intensities and their effects, whether at the level of social relations or broader structures of society (Foucault, 2008, 2014b).

Power, in turn, is presented by Foucault (2014a, 2014b) as a social practice that can be understood as a set of mechanisms and procedures that ensure its exercise. This notion regards how power relations are rationalized and reflected which, although considered as universal (e.g. sovereignty, people, subjects, state, civil society), are considered mobile, transformable and reversible. Its manifestation does not occur in an organized way, but diffuse and dispersed, under a chaotic game of forces (Foucault, 2012). This conceptual range is incidental: power has no form or body nor can it be possessed; it is transitory and exercisable (Foucault, 2014b, 2014c).

Power is a force that disperses its effects in the most varied social instances, producing a set of possibilities with which people's lives, under certain circumstances and contexts, become standardized and directed (Foucault, 2008, 2012). Thus, the exercise of power is operationalized by different instances that produce social spaces capable of providing an understanding of how social practices can objectify or subjectify; it is not linked to the execution of restrictive, but productive actions (Foucault, 2014b, 2014c).

Power exercises emerge from the way that dispositifs direct and operate certain strategies that support the driving possibilities of individuals (Foucault, 2008, 2014b). Dispositifs concern networks developed from institutions, norms, government apparatus, social and discursive practices that converge in systematic groupings, allowing the operation of power (Foucault, 2012,2014a). Thus, dispositifs support the way in which power operates and can be exercised by any entity (e.g. government, institutions, organizations, individuals) that appropriates them (Foucault, 2008, 2014c). This is because the dispositifs are based on truths and behaviors established in the social fabric, through the negotiation of different socially constituted knowledge (Foucault, 2014c, 2016).

\section{Methodological procedures}

Aligned to the theoretical foundation of the study, we adopted the genealogy of power as a research method, which reveals dispositifs operated by power diagrams in a certain context (Foucault, 2014b), a poststructuralist approach, adherent to CCT investigations (Arnould \& Thompson, 2015; Jantzen, Fitchett, Østergaard \& Vetner, 2012). The method is an expansion of Foucault's first theoretical-methodological cycle (i.e. archeology of knowledge), advancing from the analysis of discursive practices to nondiscursive practices (Foucault, 2014b).

Thus, the genealogy of power has its starting point at the discursive formations, having its analytical point of arrival the identification of power diagrams, which refers to a map of relations of discursive and nondiscursive forces. To extrapolate from discursive formations to power diagrams, genealogical analysis focuses on power operators, that is, on the identification of how power is exercised in a certain context (Foucault, 2010, 2014b). Table 1 presents the power operators criteria formation as categories of analysis.

The concatenation between the three levels of analysis (i.e. discursive formations, power operators, power diagrams) allows the identification of dispositifs. Figure 1 illustrates this process.

As an empirical locus, we collected data from interactions by ASoIaF fans about GoT on the Westeros.org platform. This is the most notorious portal on the fictional universe and the platform that brings together the largest number of fans in the saga (Young, 2014). Besides, the site features a series of discussion forums and a rich set of data that address the research problem. The site is organized into topics of fan interest about the saga, including different aspects of the TV series. One specific forum dwells on the discussion of each episode of the series. We collected every comment posted on it. Thus, the data cover all messages published 


\begin{tabular}{ll} 
Criteria & Definition \\
\hline Differentiation systems & $\begin{array}{l}\text { Every power relationship operates differentiations that work, simultaneously, as } \\
\text { conditions and effects of such relationship. Thus, differentiation systems allow one } \\
\text { to act on the actions of others. Such systems can be the most varied, such as legal, } \\
\text { social, economic, linguistic, cultural, etc }\end{array}$ \\
Power relationships presuppose certain purposes. Thus, the types of objectives \\
relate to the purposes of those who act on the actions of others. Such objectives can \\
be numerous: to obtain or maintain privileges, to profit, to be recognized or valued, \\
to perform tasks among others
\end{tabular}

Source(s): Adapted from Foucault (2010, 2014b)
Resisting to Game of Thrones

Table 1.

Training criteria for power operators

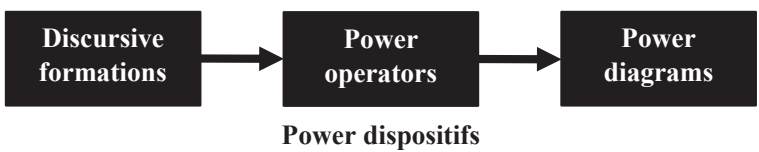

Source(s): Adapted from Foucault (2010, 2014b)

Figure 1. Steps in the analytical process

on the 73 episodes of the eight seasons, produced between 2011 and 2019, in a total of 19,660 comments.

\section{Data analysis description}

This section presents the results of the three levels of analysis in specific subsections, as shown in Figure 2. In the first subsection, the discursive formations are described, discussed through the empirical contexts they were elicited and illustrated through examples taken from the data. The same process occurs in the next subsection, regarding power operators, having their training criteria that (see Table 1) discussed. In the third subsection, the description of the power diagrams elicited in the analysis is presented. On that occasion, the data examples explore the complete set of relationships (i.e. discursive formation-power operator-power diagram). It is worth saying that in the three sections, the same data examples were used in order to evidence the congruent set of relationships between the categories.

The two power dispositifs inferred from this analysis accrue from both the singular and overlaid flows represented in Figure 2.

The power dispositifs are presented in the subsequent section, in the form of articulation and reflection in the light of the theory. This results from an interpretation of the results in the light of Foucault's theory and in view of the socio-cultural context of the investigation. 


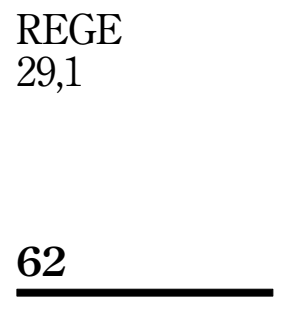

Figure 2.

Set of relationships between categories

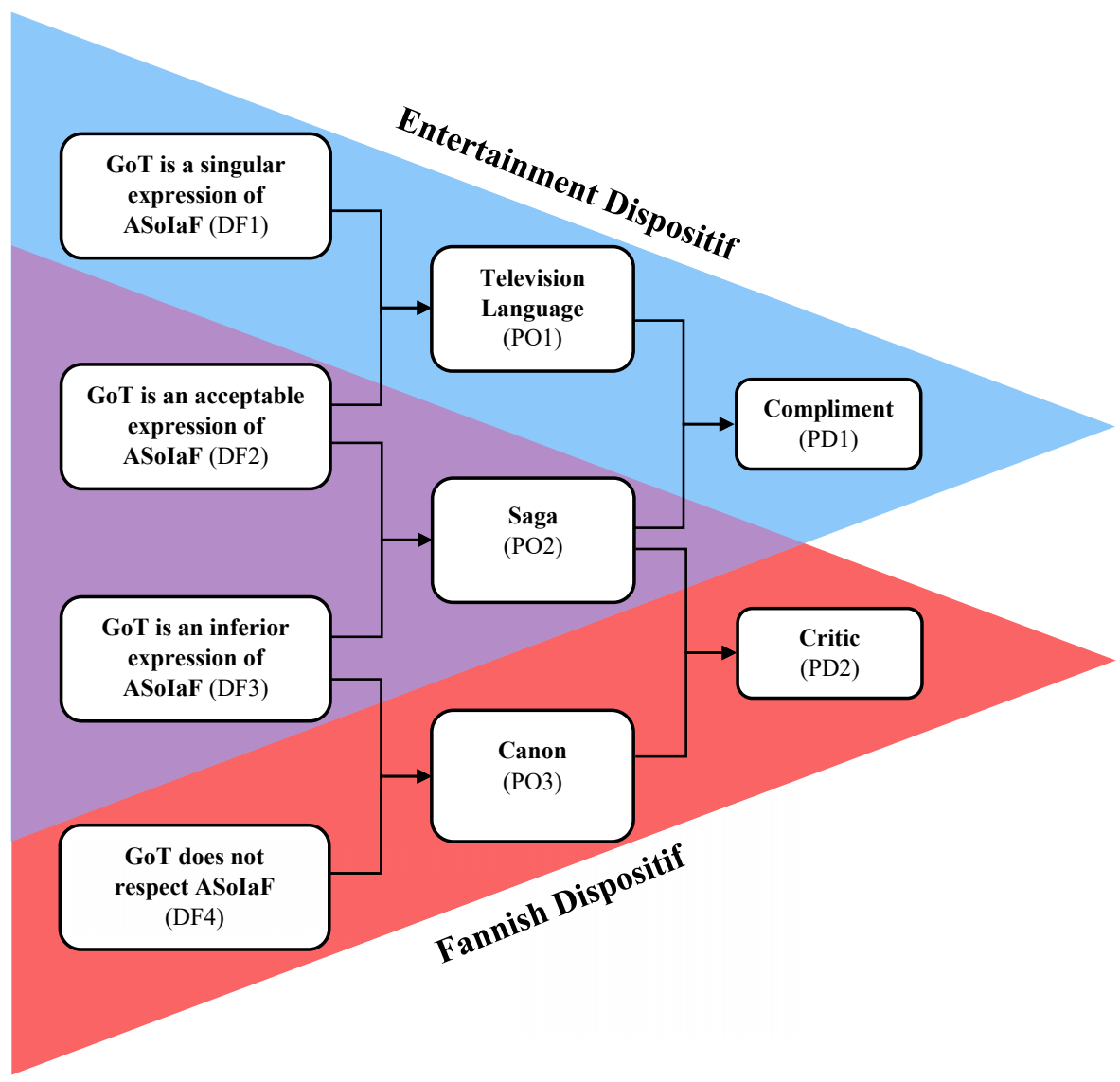

Discursive formations

The four discursive formations revealed by our analyzes refer to the way in which the series was adapted from books, against the background of the differences between literary and television languages. They show a certain gradation in the understanding of how this process took place.

On the one hand, reports on the fandom indicate that GoT is a singular expression of $A$ SoIaF (DF1). This formation establishes the series as a faithful version of the canon. There is an understanding that the television narrative requires adaptations to the original text, but that this is done in a reliable manner. In addition, audiovisual production is understood as a means of expanding the experience of enjoying the saga, as well as its fan base. Figure 3 presents the message of a fan who exemplifies such discursive formation.

The messages bring a fan's message when ponders criticism from other fans about the direction the series begins to take in the fifth season. At this stage of the production, some GoT plots had already reached the last published book by ASoIaF (i.e. A Dance of Dragons), then needing to produce original content that until then books fans were unaware of. In the highlighted message, the fan rejects the perspective of another member of the forum, emphasizing that it does not make sense for HBO to finish its most successful series just because it diverges from the books that inspire it. More than that, the fan believes that 
Considering the large mess, that the showrunners have to work with, I think they do an excellent job of streamlining it and bringing it to the screen. I enjoy the show and l enjoy the books. You do understand that no one is forcing you to watch show? If they put everything that is in those overblown, unedited books into the show, it would be 1000 hours of just meandering drivel and that would not be much fun to watch.

Source(s): Retrieved from https://asoiaf.westeros.org/index.php?/topic/127545-how-would-you-rate-episode-501/page/5/ \#comments [Accessed Jun 29, 2021]

Figure 3. Empirical example 1

watching GoT expands the possibilities for ASoIaF readers. It is, therefore, a material that is both unique for the particularities of the television media and for allowing the fan to (re) enjoy the narrative in unprecedented ways. Consequently, it is a perspective that reflects another discursive formation.

In the same line of reasoning, but externalized in a less enthusiastic way, reports show that the adaptation of the books is not entirely reliable; however, considering the characteristics of television production, it is presented as adequate. Thus, it is understood that GoT is an acceptable expression of ASoIaF (DF2), which enables an immersive entertainment experience.

On the other hand, there is an understanding that the series distances from the canonical universe of the books. A more comprehensive version of this position recognizes the inevitable need to adapt the work to television language but resents that the way this is done could be more aligned with the original work. Thus, despite recognizing qualities in the series, it is understood that GoT is an inferior expression of ASoIaF (DF3).

A message published about the final episode of the fourth season (see Figure 4) illustrates these two discursive formations. It is produced in the moment that the narrative of the television program presented the first indications that it would distance itself from the books. The fan recognizes the validity of GoT for his media. However, as a fan of ASoIaF, he is forced to compare the two narratives beyond the limits of the media, considering the inferior adaptation. He considers it to be the consequence of narrative freedoms that the producers performed in previous seasons - in killing characters still alive in books - and because GRRM has not yet published the end of the story. Both aspects prevent the fan from stating that it is impossible to consume both media and be satisfied with both.

The most radical version of the fan's position expresses that GoT does not respect ASoIaF (DF4). The reports that support this formation argue that the language differences between literature and television do not justify the narrative freedoms of the series. The understanding is that there is an orientation toward the search for a wider audience at the expense of the quality of the work, which, in the end, denigrates its legacy and produces fans of the television program who do not access the richness of the fictional universe. The message presented in Figure 5 brings lights on it.

In the message of this fan, it is visible that there is a movement within the fandom to reject GoT as an adaptation of ASoIaF for having taken a course that does not match the logic of the literary narrative. In this perspective, technical aspects of the series (i.e. cast performance, special effects) are praised, but only as elements that alleviate the successive narrative failures that have become, for part of the fandom, increasingly constant in their final seasons. 


\section{REGE 29,1}

\section{4}

Figure 4.

Empirical example 2

Figure 5.

Empirical example 3
Posted June 16, 2014

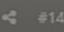

Based purely on it being a tv show and series, I give the episode a 10. Great TV. I give the season a 9, by far the best TV season of the series.

As a book reader and fan of the books first I am a bit disheartened by how far they are deviating from the books now. I understand why they have to do it, but the story is so much better in the books. It is more intriguing and I really dislike that they are now spoiling certain things for book readers to make their show better. The main thing from this episode was Jojens death, I mean I figured he was probably going to die in the books, but he is more of an important character than a lot of the side characters they have killed so far, like Irri, Grenn, Pyp, etc. it bugs me that they are taking advantage of their advance knowledge of events.

And that is partially GRRM's fault to for giving that information up and selling out the series before he finished the book. Couple that with the snails pace he writes at and it really is a big issue. I've lost some respect,for him to be honest. Anyways, I love the series, it is the best show on $t v$, but I may have to hold off on finishing it for when the books all come out. Sadly, I don't think I can have both and be satisfied.

Like I said though, that was a great episode of tv.

Source(s): Retrieved from https://asoiaf.westeros.org/index.php?/topic/112364-how-would-you-rate-episode-410/page/8/ \#comments [Accessed Jun 29, 2021]

$3 / 10$ for technical execution and music.

The plot rushing destroys the whole series.

Varys had to end, but his entire arc was viciously cut short and he had a memorable talk last episode, truly a shame. And Jon Snow is useless again, all hope in that character goes up in smoke.

Not only KL is burning but entire character arcs. The bell ringing madness was sadly hilarious. And Harry Strickland got 5 minutes of screen time only to die running away. That's not the man of the books, it's a mockery. The GC, a famed militia, just anonymously reduced to ashes.

Scorpions are suddenly useless after making a quick kill of Rhaegal, it just suits the plot writing.

Euron dies the cartoon villain death he "deserves".

The death of Cersei and Jaime was a letdown, no special circumstances, just buried beneath the rubble.

And there's a final mockery with small wildfire caches burning in the city. It's like saying "OK, you fools were right that wildfire would burn KL"

Cleganebowl lasted a longer time than I thought but it's not really satisfying. And so also ends our beloved Qyburn, cut short like other characters.

You almost hope this whole season was Bran's vision of unlikely events...

Source(s): Retrieved from https://asoiaf.westeros.org/index.php?/topic/154435-how-would-you-rate-episode-805/page/6/ \#comments [Accessed Jun 29, 2021]

\section{Power operators}

The gradation identified in the discursive formations reveals visions in relation to the way GoT narratively translates ASoIaF which, despite being ultimately contrary, cannot be considered radically antagonistic. If, on the one hand, we evidence two opposing discursive formations, it is possible to put these attitudes into perspective because there are more compliant formations in the support (DF2) and in the criticism (DF3) for the series. As well as the fact that those discourses are not radical in their fundamentals since the reliability of the canon is evoked in the support (DF1), and the singularity of the television language is recognized in the criticism (DF4). Thus, such discursive formations reveal three power operators that maintain a gradual logic, but in an even more convergent sense. Of three operators, two present the opposite positions in relation to the television adaptation, but in versions not radically conceived, while another represents a balanced version between such positions. 
Television language (PO1) legitimizes GoT and is derived from the conceptions that the series is both a singular expression (DF1) and an acceptable expression (DF2) of ASoIaF. The fan reports that support this position argue that the series is an adaptation of the literary work and, therefore, needs to have autonomy to translate it into a language (i.e. television) different from the original (i.e. literary), which is done properly. On the other hand, these fans recognize the need for this language to be more accessible than the original work, since the market logic that governs television is more inclusive, which, ultimately, can contribute to the increase of fan base of the fictional universe.

This operator is supported by two differentiation systems clearly linked to specific types of objectives. On the one hand, fun (differentiation system) refers to a recreational fruition, uncompromised with great reflections on the content consumed, which reveals the purpose of enjoying the series as a hedonic experience (type of objective). On the other hand, seriefilia (differentiation system) concerns the logic of consumption of television programs of a serial character, whose format presents a narrative structure accessible to a wide audience, which is seen as a way to expand the experience with the fictional universe (type of objective), either by the audiovisual resources that the books do not have or by the fact that GoT advances in the story of the still unfinished literary work.

These two paths converge in the understanding that audiovisual (instrumental modality) enhances the experience of enjoying the fictional universe of ASoIaF. Such an understanding, in turn, leads these fans to argue that the series is part of the fictional universe (degree of rationalization), following the canon in line with the characteristics of television production. Thus, television is shown as the form of institutionalization that rules and disciplines the way these fans relate to GoT and ASoIaF.

Returning to the fan comment shown in Figure 3, it is possible to observe how this operator works. When the fan is positive about the television version form of institutionalization) of the fictional universe, he/she considers that the audiovisual format (instrumental modality) expands the possibilities to consume the saga. It is an alternative and autonomous version which is fun (differentiation system) and allows audience to a hedonic experience (type of objective). Likewise, GoT focuses on key moments in ASoIaF - otherwise it would reach more than 1000 hours - differentiating itself by the seriefilia, which holds to experiences that expand fans' relationship with the saga (type of objective). Consequently, the fan considers that the series is part of the fictional universe (degree of rationalization), since it allows to fandom poach, a new and valid version from cultural object. In contrast, Canon (PO3) establishes ASoIaF as the basis for any transmedia extension work in the franchise. It derives from the arguments that GoT does not respect ASoIaF's legacy (DF4) or at least does not appropriate it as it should (DF3). Fans who position in this way demonstrate profound knowledge of the books and take responsibility for preserving their foundations (e.g. knowledge, values, aesthetics), as well as guiding fans who migrate from the series to the literary work. They argue that they understand that a television adaptation requires adjustments, but that this should not suppress or alter points that they consider important.

In total, two differentiation systems underlie this power operator: the fictional universe, which concerns the founding basis of the canon for any adaptive form of the work, and productivity, which refers to fan activities in the dissemination of this canon and how it has been appropriated in the series. Both reveal the objective of preserving the canon. The former, though, signals the possibility that other media may expand the ASoIaF experience, but that the series has failed in this.

Thus, the canon is assumed to be a dogma (instrumental modality) of any manifestation based on ASoIaF, with the literary work being understood as a canonical text form of institutionalization) that has its own system of rules and values. Therefore, adaptations must be reliable (degree of rationalization) or they cannot be considered as part of the fictional universe.

Resisting to Game of Thrones 
REGE 29,1

\section{6}

The message sent by the fan highlighted in Figure 5 gives clues as to how this operator is exercised. The way the series discarded characters and scenarios from the books is considered a mockery, indicating how the fan considers adaptations must be reliable (degree of rationalization). In the comment, the fan evokes that books' perspective is the canonical text (form of institutionalization) and should be preserved (type of objective). Therefore, this attests to the existence of a dogma (instrumental modality): to the fan, it is better that the whole final season of GoT is a plot from a character illusion (i.e. Bran's vision of unlikely events) than equivalent or an adaptation of the conclusion of ASoIaF. In this effort, two differences must be attested by the fandom: the fictional universe established in the books is the only one to be considered valid and how fans have to act in a productivity way to make the show's narrative a discarded version.

Among the previous positions, derived from the understanding that the series is an inferior (DF3), but acceptable (DF2) expression of ASoIaf, the Saga (PO2) supports the idea that the story conceived by GRRM has the quality necessary to be told in different media. Fans who follow this understanding maintain that, as long as they consider the canon as a narrative basis, the television adaptation contributes to an expansion of the reach of the saga, contributing with possibilities not present in the books, either by the media limitations or by the hiatus of its releases.

Some of the criteria that support this operator also make up the other operators, but they are manifested differently. The purpose is to expand the experience of enjoying the saga. This type of objective is common to the three operators. In the present incarnation, it is based on the differentiation systems of the other operators that deal with the narrative and technical aspects on which both the series and the books are developed (i.e. seriefilia and fictional universe), as well as in their instrumental modalities (i.e. audiovisual and dogma). Thus, it is assumed that the series must, in some instance, be based on the canon, but without losing sight of its own potential.

This path presents unique aspects of this operator. What rules this view of conformity is the sociability (form of institutionalization) established among fans of less impetus in relation to the series or books. They understand that the best of both languages can be made compatible (degree of rationalization) and that this view brings fans together in their different perspectives on the saga.

The operator can be seen in the fan movement attested in Figure 4. In the highlighted message, the fan establishes that there is validity in consuming both versions of the saga, pointing out that the best of both languages can be made compatible (degree of rationalization). On the one hand, the fan considers that the audiovisual media is an instrument, which differs to allow the audience consecutive surprises, following the logic of seriefilia. On the other hand, the fan regrets the spoilers of the book (i.e. death of characters), a dogma (instrumental modality) that differentiates the fictional universe. In both cases, the fan reinforces that it is possible to socialize the two media (form of institutionalization), since each one in its singularity aims to expand the fans' joy (type of objective) in consuming the saga.

\section{Power diagrams}

From the gray areas that the analysis has revealed so far, two power diagrams are identified: one of praise and other of criticism of the series. They themselves are grayish; it is not an apologetic praise or a radical or destructive criticism. Thus, they can be understood as the very argumentative basis on which power relations are based, which occurs due to the nonexclusion between the elicited categories.

Compliment (PD1) diagram maps how the series is legitimized in the fandom. Television language is seen as a contribution to the saga, as it expands its narrative possibilities and audience reach. It is based on the possibility of a hedonic experience and the expansion of the fan base, culminating in a potentialized community. Such a favorable position to GoT is 
unique when considering the elements that make up the television language operator (PO1) as autonomous. These, in turn, are based on the perception of the series as a particular expression of ASoIaF (DF1) or as an adaptation that needs to take liberties capable of adding to the fictional narrative (DF2). To highlight this analytical convergence, we revisit Figure 3, in which a fan defends that GoT is an autonomous and so does not need to attend the entire ASoIaF fandom (see Figure 6).

On the comment, a fan considers that GoT fulfills its role as a television program for having achieved the status of best show in its segment. This conception recognizes the television series as successful (PO1), which, in turn, considers both the overcoming of difficulties inherent in the production of such a great show (DF1), and the adaptation of sinuous characteristics of the literary plot to a medium that requires more emotion (DF2).

From another perspective, Critic (PD2) diagram sustain the supremacy of the books over the series. The canon established in the literary work is understood as the cornerstone that must not be distorted. It is a hedonic cognitive experience, so to speak, in which the knowledge of the work defines the fan's relationship with the fictional universe, which, consequently, must be preserved and propagated in a reliable manner. Transposition to TV is not seen as a problem, but the understanding that the adaptation has deteriorated to the point of distorting the canon narrative is the target of the developed criticism.

The contesting practices in relation to the television series (PD2) are unique in that they constitute an appeal to a reliable adaptation present in the canonical operator (PO3). This, in turn, is linked to knowledge that expresses the inferiority of the television program in relation to the content that gave rise to it (DF3) or the need to honor this (DF4). This understanding is evident from a fan's message highlighted in Figure 5 (see Figure 7).

In the assessment, a fan considers that the hasty way of conducting the series narrative has ruined the show. When describing how the plots of different characters from the fictional universe were adapted in a way that is not very consistent with their literary counterparts, the fan rejects the show's outcome for not following the logic of the books. Such arguments consider the television series as invalid to the canon (PO3) because it does not present a content reliable to what exists in the books' fictional universe (DF3), as well as for disrespecting its logic and particularities (DF4).

However, there is a commonality between positive (PD1) and negative (PD2) perceptions regarding the validity of GoT for ASolaF. Such convergence is present in the understanding that the television series contributes in some way to the fictional universe (PO2), whether at an acceptable level (DF2) or even lower (DF3). This nuance can be seen in a message in which a fan indicates how there are two ways of watching the show (see Figure 4) (see Figure 8).
Resisting to Game of Thrones

LOL That would not be a good business decision and so it's a good thing for $\mathrm{HBO}$ investors that you are not running HBO. You do know that the show is their most successful series, even surpassing The Sopranos.

Considering the large mess, that the showrunners have to work with, I think they do an excellent job of streamlining it and bringing it to the screen. I enjoy the show and I enjoy the books. You do understand that no one is forcing you to watch show? If they put everything that is in those overblown, unedited books into the show, it would be 1000 hours of just meandering drivel and that would not be much fun to watch.

Figure 6. Empirical example 1 (Figure 3 reprinted) 
REGE

29,1

\section{8}

Figure 7.

Empirical example 3 (Figure 5 reprinted)

$3 / 10$ for technical execution and music.

The plot rushing destroys the whole series.

Varys had to end, but his entire arc was viciously cut short and he had a memorable talk last episode, truly a shame. And Jon Snow is useless again, all hope in that character goes up in smoke.

Not only KL is burning but entire character arcs. The bell ringing madness was sadly hilarious. And Harry Strickland got 5 minutes of screen time only to die running away. That's not the man of the books, it's a mockery. The GC, a famed militia, just anonymously reduced to ashes Scorpions are suddenly useless after making a quick kill of Rhaegal, it just suits the plot writing. Euron dies the cartoon villain death he "deserves". The death of Cersei and Jaime was a letdown, no special circumstances, just buried beneath the rubble. And there's a final mockery with small wildfire caches burning in the city. It's like saying "OK, you fools were right that wildfire would burn $\mathrm{KL}$

Cleganebowl lasted a longer time than I thought but it's not really satisfying. And so also ends our beloved Qyburn, cut short like other characters.

You almost hope this whole season was Bran's vision of unlikely events...

Source(s): Retrieved from https://asoiaf.westeros.org/index.php?/topic/154435-how-would-you-rate-episode-805/page/6/ \#comments [Accessed Jun 29, 2021]

\section{Posted June 16, 2014}

Based purely on it being a tv show and series, I give the episode a 10. Great TV. I give the season a 9, by far the best TV season of the series. As a book reader and fan of the books first I am a bit disheartened by how far they are deviating from the books now. I understand why they have to do it, but the story is so much better in the books. It is more intriguing and I really dislike that they are now spoiling certain things for book readers to make their show better. The main thing from this episode was Jojens death, I mean I figured he was probably going to die in the books, but he is more of an important character than a lot of the side characters they have killed so far, like Irri, Grenn, Pyp, etc. it bugs me that they are taking advantage of their advance knowledge of events.

And that is partially GRRM's fault to for giving that information up and selling out the series before he finished the book. Couple that with the snails pace he writes at and it really is a big issue. I've lost some respect,for him to be honest. Anyways, I love the series, it is the best show on tv, but I may have to hold off on finishing it for when the books all come out. Sadly, I don't think I can have both and be satisfied.

Figure 8 .

Empirical example 2 (Figure 4 reprinted)
Like I said though, that was a great episode of tv.

Source(s): Retrieved from https://asoiaf.westeros.org/index.php?/topic/112364-how-would-you-rate-episode-410/page/8/ \#comments [Accessed Jun 29, 2021]

For the fan, the entertainment capacity of the show must be praised, but certain narrative choices must be criticized. As a television program, GoT seems impeccable, mainly for its technical and visual merits. However, because it is an adaptation of ASoIaF, such a complex fictional universe, advancing content not yet explored in the book series puts its development in check. The fan considers the show valid for the saga as a whole (PO2), even if it bothers him personally. The quality in the way the content of the fictional universe is presented in the television series (DF2) is opposed to the superficiality in the way that the plot of certain characters is conducted (DF3).

\section{Between entertainment and fannish}

The representation of two large sets of relations between the categories of the research indicates that the power relations in the forum occur through two dispositifs (see Figure 2). 
We understand the first of these as Entertainment, a dispositif that guides the enjoyment of the series based on a logic of fun, naturalizing consumption as a hedonic practice. Gray (2010) states that entertainment precedes the industrial structures of modernity, being marked by a secular historicity, rooted in practices that refer to medieval carnivals. Stebbins (2017), in turn, argues that entertainment is a system that includes an industry, content, its creators and performers but also the audience and, ultimately, the social structure.

Thus, the standards set by the entertainment industry are not followed blindly by fans; when interacting and interpreting content created for marketing purposes, they actively resignify and reuse them for their own purposes (de Souza-Leão \& Costa, 2018; Zajc, 2015). Based on an indepth knowledge of what they consume, fans validate and expand the reach of the media text, through their activities, to share experiences (Hackley \& Hackley, 2018; Mittel, 2015).

Based on this, we argue that entertainment consumption is an economically permeated social relationship. In this line of reasoning, we understand that fans can be understood as the homo oeconomicos discussed by Foucault (2008). The philosopher inserted economic biopower as an inescapable instance, superimposed on everyday life and thus present in people's routine practices. Thus, the homo oeconomicos engenders a lifestyle that expresses the protagonism of economic truth over any other. However, he does not present this critical view as if we live in a system that simply imprisons. Consistent with his theorizing about power, the French thinker argues that the same techniques for exercising economic biopower are appropriate as a form of resistance; people learn their rules and start to deal with them according to their purposes.

On the other hand, Fannish dispositif represents the set of practices, rites and values that characterize the way fans consume. These aspects are articulated amidst a system of activities, norms and worldview and, thus, characterize a particular culture (Jenkins, 2015; Hills, 2002). That is how fans mobilize and react to the entertainment industry. According to Hills (2002), a fundamental characteristic of fan culture is to be positioned between consumption and resistance.

This positioning is primarily provided by the technological appropriation inherent to participatory cultures that allow the consumption of popular culture to be, at some level, autonomous in relation to marketing practices (Fuschillo, 2016; Lanier Jr, Rader \& Fowler III, 2015). It is not, however, a search for destruction of the entertainment system, but a mitigation of the distance between media production and reception (Chen, 2021; de Souza-Leão \& Moura, 2018).

We understand that this dispositif reveals how the fan expertise is linked to what Foucault (2014c) defines as experience. For the philosopher, experience refers to the way in which knowledge and the will of individuals are articulated when they simultaneously are governed and govern themselves. Self-government is manifested through the relationship between socially defined truths. Thus, while the subject agrees to submit to certain rules, it also resists to certain practices and norms.

The dispositifs are not dichotomous (i.e. antagonists); they reveal modulations of meanings that represent different moderating structures of the fans' conduct. While the fannish dispositif claims that the truth of the fictional universe lies in the books (i.e. canonical), the entertainment dispositif presents an autonomous truth (i.e. television program). Both are truths external to the fandom: one from literature; other from television. What is at stake for fans is, ultimately, a dispute between these truths.

According to Foucault (2016), the game of truths is a process of veridication, in which different knowledge is put to the test, being negotiated, and assimilated or rejected. Power relations and, consequently, resistance appear amid certain games of truth, as they raise, among different possible discourses, what can be said to be true in each context.

We understand that these modes of resistance represent different degrees of fan positioning in relation to the adaptation of the media text. However, they are far from
Resisting to Game of Thrones 
REGE

29,1

signifying extremes that represent passive acceptance or a radical break. This is what promotes dialogue and productivity of fans in the same social space, despite their disagreements. We conclude that this process occurs in the form of an agonism in Foucault's terms, in which conflicts are understood as positive and fought to relativize the discourses of truth and to respect differences.

Foucault (2010a) conceives that the relationship between forces of power exercises and their consequent resistances does not lie on antagonism, but on agonism. The agonistic relationship is characterized by a struggle based on mutual encouragement, not seeking nullity from one party to another (i.e. antagonism).

This Foucauldian proposition echoes Nietzsche when he considers that moral arguments allow the rationalization and justification of how power relations are mutual agonist influences and not forms of complete domination that antagonize agencies. In this perspective, Foucault (1977) considers that moral narratives are usually evoked through the reproduction of differences and social status that do not explicitly invoke aspects of the dispositif, its diagrams and operators that shape it. This can be seen in the agonistic way that consumers can use their cultural capital to establish an anti-antagonism relationship (Kozinets \& Handelman, 2004; Luedicke, Thompson \& Giesler, 2010). On the one hand, it can be understood as an Apollonian relationship with what they consume, by characterizing tastes as vulgar or desirable; on the other hand, consumers can use themselves (i.e. their bodies, position in market subcultures) to elaborate a Dionysian relationship with the existence that allows them to live in a way which attends to their wills (de Oliveira et al., 2019; Roux \& Belk, 2019).

Agonist relations are presented by Nietzsche (2006) as aesthetic principles which conceive social environments from the dispositions of human nature. The agonistic dispute is ruled by the contradiction and mutual play of agents that compete with each other, where there is no truce between the different parties, but there is also no annihilation of these. It is an ontology of anti-antagonism that occurs through the dispute between the Apollonian and the Dionysian: where wills and moralities are simultaneously conducted and manifested, which are not capable of being completely dominated, but which continually affect each other.

In order to present how agonism works, Foucault (2010a) deals with the possibility of freedom in the exercise of power, a fundamental condition for it and what made possible precisely by resistance. Agonism is permeate power relations permanently; it is an explicit way in which different statements (i.e. knowledge) differ and influence a transgression that temporarily denies preestablished limits until new limits appear. Such statements work as provocations to improve the basis that support different conceptions of truth constitution; thus, it becomes a relationship of synergy that is, mutually, productive and ethical. This process makes possible to delineate how agonism permeates the constitution of an ethical subject (Foucault, 2004).

\section{Concluding remarks}

Our investigation indicates that fans of media products resist the changes made by the entertainment industry in relation to their canon through a modulation of opinions that intend to constitute them as true. On the one hand, the entertainment dispositif indicates a resistance that grows from reflexive acceptance to categorical criticism. The positioning of fans who consider the adaptation as autonomous to the content that originates it legitimizes the difference from the enjoyment of different media, but not without taking a stand on this matter and without even refraining from indicating problems in the process. On the other hand, the fannish dispositif reveals a resistance that runs from a constant criticism to a 
qualified acceptance. Fans who take a strong stance to set limits on the way media text is adapted, but not without recognizing the limits of this task.

The agonistic relationship between the dispositifs reveals that different forms of consumption resistance not only coexist but are productive with each other. It is possible, then, to understand how transgressions of market knowledge performed by prosumers (e.g. fans), aligned or not to the interests of producers, are productive in perpetuating the consumed product. This reveals that forces linked to powers exercised in the market affect each other, without objecting to the nullity of others.

The study endorses Michel Foucault's conception of power as fruitful for consumer research. The findings point to an understanding of how consumers can simultaneously be led to incorporate and resist marketing practices (Denegri-Knott \& Tadajewski, 2017; Mikkonen \& Bajde, 2013); how marketing strategies can both function as a way of governing consumers and of stimulating their resistance (Bokek-Cohen, 2016). Still, our research expands the discussion that there are negotiations of moralities in the marketing sphere (see Holt, 1997; Luedicke et al., 2010).

In this sense, present research combines the perceptions that market interactions function as an arena for the exercise of resistances (see Canniford \& Karababa, 2013; Denegri-Knott \& Tadajewski, 2017) and those who consider that fan interactions are commonly established by conflicts inherent in the structure of fandoms (see Hewer et al., 2017; Fuschillo, 2020). Specifically, it presents how different forms of consumer resistance co-exist in agonist relations, expanding CCT's epistemological perspectives that deal with market conflicts between agents that assume similar roles in this.

This is an extension of those that evoke the concept of Nietzschean agonism (see de Oliveira et al., 2019; Luedicke et al., 2010), as Foucault (2010a) himself seeks to indicate how his contribution on the subject, the possibility of freedom exercises that go beyond the context in which they coexist is reflected. Therefore, it presents CCT studies with an ontological appeal, in which researchers in the field can reflect on freedom exercises from different conflicts guided by autonomous consumer resistance in their public manifestations about what they consume.

By focusing on the relationships between fans and media products, our research also contributes to an emerging interdisciplinary approach between consumer research and fan studies. Despite the understanding that fan practices express political identities (Booth, 2018; de Souza-Leão \& Moura, 2018), the notion that fan behavior is reduced to a search for new media content still prevails (Jenkins, 2015), what would docilize them through preeminent power structures present in the entertainment industry (Chen, 2021; Ryalls, 2016).

On the other hand, the systematic of the Foucauldian genealogical method worked on in our investigation can be understood as a methodological contribution to consumer research. As it is a philosophical method, we understand that its transposition to social research requires care regarding systematization aligned with the modus operandi of qualitative research, an aspect not identified in other works that use the approach (see Chen, 2021; Hunter, 2018; Zajc, 2015). Since theory and method in Michel Foucault's ulterior work are inseparable, this approach can contribute to the adoption of its theoretical framework as a valuable alternative for the field of CCT (Denegri-Knott \& Tadajewski, 2017; Thompson et al., 2013).

In order to expand the discussion initiated in the present study with a view to theorizing consumption and resistance following Foucault's theory, future investigations could focus on other fandoms and social arrangements of fans of different media products, such as games adaptations to television shows and film productions (e.g. The Witcher, Sonic, Tomb Raider), remake or continuations of classic films (e.g. The Invisible Man, Blade Runner) and spinoff series to stream services (e.g. The Mandalorian, WandaVision).
Resisting to Game of Thrones 
REGE

29,1

\section{References}

Arnould, E., \& Thompson, C.J. (2015). Introduction: Consumer culture theory: Ten years gone (and beyond). Consumer Culture Theory, 17(1), 1-21.

Bhattacharjee, A., Berger, J., \& Menon, G. (2014). When identity marketing backfires: Consumer agency in identity expression. Journal of Consumer Research, 41(2), 294-309.

Bokek-Cohen, Y.A. (2016). How are marketing strategies of genetic material used as a mechanism for biopolitical governmentality?. Consumption Markets \& Culture, 19(6), 534-554.

Booth, P.J. (2018). Framing alterity: Reclaiming fandom's marginality. Transformative Works and Cultures, 28, doi: 10.3983/twc.2018.1420 [Accessed 29 Jun 2021].

Boyaval, M., \& Herbert, M. (2018). One for all and all for one? The bliss and torment in communal entrepreneurship. Journal of Business Research, 92, 412-422.

Bryce, D., MacLaren, A.C., \& O'Gorman, K.D. (2013). Historicising consumption: Orientalist expectations of the Middle East. Consumption Markets \& Culture, 16(1), 45-64.

Canniford, R., \& Karababa, E. (2013). Partly primitive: Discursive constructions of the domestic surfer. Consumption, Markets \& Culture, 16(2), 119-144.

Chen, Z.T. (2021). Poetic prosumption of animation, comic, game, and novel in a post-socialist China: A case of a popular video-sharing social media Bilibili as heterotopia. Journal of Consumer Culture, 21(2), 257-277.

Clapton, W., \& Shepherd, L.J. (2016). Lessons from Westeros: Gender and power in game of Thrones. Politics, 37(1), 5-18.

Clark, T. (2019). How 'Game of Thrones' viewership compares with TV's other most-watched shows, Available at: https://www.businessinsider.in/how-game-of-thrones-viewership-compares-to-tvsother-most-watched-shows/articleshow/68945594.cms [Accessed 29 Jun 2021].

Coskuner-Balli, G. (2020). Citizen-consumers wanted: Revitalizing the American dream in the face of economic recessions, 1981-2012. Journal of Consumer Research, 47(3), 327-349.

Cronin, J., \& Hopkinson, G. (2018). Bodysnatching in the marketplace: Market-focused health activism and compelling narratives of dys-appearance. Marketing Theory, 18(3), 269-286.

De Certeau, M. (1984). The practice of everyday life. Berkeley, California, CA; Los Angeles, California, CA; London: University of California Press.

de Oliveira, R.C.D A., Chevitarese, L., \& Ayrosa, E.A.T. (2019). The tragic consumer: A Nietzschean reading of irremediably unsatisfactory consumption. Latin American Business Review, 20(2), 157-183.

de Souza-Leão, A.L.M., \& Costa, F.N. (2018). Assemblaged by desire: Potterheads' productive consumption. RAE-Revista de Administração de Empresas, 58(1), 74-86.

de Souza-Leão, A.L.M., \& Moura, B.M. (2018). Temos que pegar todos! Discursos identitários sobre o consumo de Pokemon GO no Brasil. Revista Brasileira de Marketing, 17(6), 895-913.

Denegri-Knott, J., \& Tadajewski, M. (2017). Sanctioning value: The legal system, hyper-power, and the legitimation of MP3. Marketing Theory, 17(2), 219-240.

Ellis, P. (2019). The internet is not happy about last Night's explosive game of Thrones, Available at: https://www.menshealth.com/entertainment/a27451603/game-of-thrones-fan-reactions-season-8episode-5/ [Accessed 29 Jun 2021].

Feldman, D. (2019). Game of Thrones': By the numbers. Forbes, Available at: https://www.forbes.com/ sites/danafeldman/2019/04/11/game-of-thrones-by-the-numbers/?sh=73aa3a9d1685 [Accessed 29 Jun 2021].

Foucault, M. (2004). Ética, sexualidade, politica. Rio de Janeiro: Forense Universitária.

Foucault, M. (2008). Nascimento da biopolitica: Curso no College de France (1978-1979). São Paulo: Martins Fontes. 
Foucault, M. (2010). O sujeito e o poder. In Dreyfus, H., \& Rabinow, P. (Eds.), Michel Foucault: uma trajetória filosófica, 2.ed., 273-295. Rio de Janeiro: Forense Universitária.

Foucault, M. (2012). Em defesa da sociedade: Curso no College de France (1975-1976), 2nd.ed., São Paulo: Martins Fontes.

Foucault, M. (2014a). Vigiar e punir: Nascimento da prisão. Petrópolis: Vozes.

Foucault, M. (2014b). História da sexualidade, 1: A vontade de saber. São Paulo: Paz e Terra.

Foucault, M. (2014c). Do governo dos vivos: Curso no College de France (1979-1980). Martins Fontes: São Paulo.

Foucault, M. (2016). Subjetividade e Verdade: Curso no College de France (1980-1981). Martins Fontes: São Paulo.

Foucault, M., \& Foucault, M. (1977). Nietzsche, Genealogy, history. In Bouchard, D.F. (Ed.), Language, Countermemory, Practice: Selected Interviews and Essays, Ithaca, New York, NY: Cornell University Press, 139-64.

Fuschillo, G. (2016). Beyond the market: The societal influence of fandoms. Consumer Culture Theory, 18(1), 169-192.

Fuschillo, G. (2020). Fans, fandoms, or fanaticism?. Journal of Consumer Culture, 20(3), 347-365.

George, S. (2018). Watching game of Thrones in India: Notes on programme culture, television and YouTube. Interactions: Studies in Communication \& Culture, 9(3), 275-288.

Goodman, L. (2015). Disappointing fans: Fandom, fictional theory, and the death of the author. The Journal of Popular Culture, 48(4), 662-676.

Gray, J. (2010). Entertainment and media/cultural/communication/etc. Studies. Continuum: Journal of Media \& Cultural Studies, 24(6), 811-817.

Gurrieri, L., \& Cherrier, H. (2013). Queering beauty: Fatshionistas in the fatosphere. Qualitative Market Research: An International Journal, 16(3), 276-295.

Guschwan, M. (2012). Fandom, brandom and the limits of participatory culture. Journal of Consumer Culture, 12(1), 19-40.

Hackley, C., \& Hackley, A.R. (2018). Advertising at the threshold: Paratextual promotion in the era of media convergence. Marketing Theory, 19(2), 195-215.

Harju, A.A., \& Huovinen, A. (2015). Fashionably voluptuous: Normative femininity and resistant performative tactics in fatshion blogs. Journal of Marketing Management, 31(15-16), 1602-1625.

Hewer, P., Gannon, M., \& Cordina, R. (2017). Discordant fandom and global football brands: 'Let the people sing. Journal of Consumer Culture, 17(3), 600-619.

Hills, M. (2002). Fan cultures. London: Routledge.

Holt, D.B. (1997). Poststructuralist lifestyle analysis: Conceptualizing the social patterning of consumption in postmodernity. Journal of Consumer Research, 23(4), 326-51.

Hunter, K.M.B. (2018). Shopaholic stories: Tales of therapeutic addiction, governance, and political economy. Journal of Consumer Culture, 18(4), 497-519.

Jantzen, C., Fitchett, J., Østergaard, P., \& Vetner, M. (2012). Just for fun? The emotional regime of experiential consumption. Marketing Theory, 12(2), 137-154.

Jenkins, H. (2015). Textual poachers: Television fans and participatory culture. London: Routledge.

Johnson, G.D., Thomas, K.D., \& Grier, S.A. (2017). When the burger becomes halal: A critical discourse analysis of privilege and marketplace inclusion. Consumption Markets \& Culture, 20(6), 497-522.

Karababa, E., \& Ger, G. (2011). Early modern ottoman coffeehouse culture and the formation of the consumer subject. Journal of Consumer Research, 37(5), 737-760.

Kedzior, R., \& Allen, D.E. (2016). From liberation to control: Understanding the selfie experience. European Journal of Marketing, 50(9/10), 1893-1902.
Resisting to

Game of

Thrones 
REGE 29,1
Kozinets, R.V. (2001). Utopian enterprise: Articulating the meanings of Star Trek's culture of consumption. Journal of Consumer Research, 28(1), 67-88.

Kozinets, R.V., \& Handelman, J.M. (2004). Adversaries of consumption: Consumer movements, activism, and ideology. Journal of Consumer Research, 31(3), 691-704.

Lanier, C.D. Jr., Rader, C.S., \& Fowler, A.R. III (2015). Ambiguity and fandom: The (meaningless) consumption and production of popular culture. Consumer Culture Theory, 17(1), 275-293.

Lee, M., Roux, D., Cherrier, H., \& Cova, B. (2011). Anti-consumption and consumer resistance: Concepts, concerns, conflicts, and convergence. European Journal of Marketing, 45(11/12).

Luedicke, M.K., Thompson, C.J., \& Giesler, M. (2010). Consumer identity Work as moral protagonism: How myth and ideology animate a brand-mediated moral conflict. Journal of Consumer Research, 36(6), 1016-1032.

Maas, J. (2019). 'Game of Thrones' ties its own record for most emmys won by a series in a single season, Available at: https://www.thewrap.com/game-of-thrones-most-emmys-won-seriessingle-season-record-emmy-awards/ [Accessed 29 Jun 2021].

MacNeill, K. (2017). Torrenting game of Thrones: So wrong and yet so right. Convergence, 23(5), $545-562$.

Mathews, J. (2018). Cinematic thanatourism and the purloined past: The "game of Thrones effect" and the effect of game of Thrones on history. In McDaniel, K. (Ed.), Virtual Dark Tourism. Palgrave Studies in Cultural Heritage and Conflict, Cham: Palgrave Macmillan, 89-112.

McElroy, R., \& Noonan, C. (2019). Cultural intermediaries and the value of game of Thrones. In McElroy, R., \& Noonan, C. (Eds), Producing British Television Drama Local Production in a Global Era), 123-140.

Mikkonen, I., \& Bajde, D. (2013). Happy Festivus! Parody as playful consumer resistance. Consumption Markets \& Culture, 16(4), 311-337.

Mikkonen, I., Moisander, J., \& Firat, A. (2011). Cynical identity projects as consumer resistance: The scrooge as a social critic?. Consumption Markets \& Culture, 14(1), 99-116.

Mittell, J. (2015). Complex TV: The poetics of contemporary television storytelling. New York, NY, London: New York University Press.

Myers, A.J. (2017). Now I Am the master': Home video, canon, and authorship among George, Lucasfilm, fox, and fans. In Wroot, J., \& Willis, A. (Eds.), DVD, Blu-ray and Beyond. Palgrave Macmillan.

Nietzsche, F. (2006). O Nascimento da tragédia ou helenismo e pessimismo. Trad. J. Guinsburg, 2nd ed., São Paulo, Brasil: Companhia das Letras.

Obiegbu, C., Larsen, G., Ellis, N., \& O’Reilly, D. (2019). Co-constructing loyalty in an era of digital music fandom. European Journal of Marketing, 53(3), 463-482.

Parmentier, M.A., \& Fischer, E. (2015). Things fall apart: The dynamics of brand audience dissipation. Journal of Consumer Research, 41(5), 1228-1251.

Perks, L.G., \& McElrath-Hart, N. (2016). Television spoilers recast as narrative teasers. Qualitative Research Reports in Communication, 18(1), 1-7.

Ramsey, P., Baker, S., \& Porter, R. (2019). Screen production on the 'biggest set in the world': Northern Ireland Screen and the case of Game of Thrones. Media, Culture \& Society, 41(6), 845-862.

Rappas, I.A.C. (2019). From titanic to game of Thrones: Promoting Belfast as a Global media capital. Media, Culture \& Society, 41(4), 539-556.

Ritzer, G., Dean, P., \& Jurgenson, N. (2012). The coming of age of the prosumer. American Behavioral Scientist, 56(4), 379-398.

Roux, D. \& Belk, R.W. (2019). The body as (another) place: Producing embodied heterotopias through tattooing. Journal of Consumer Research, 46(3), 483-507.

Ryalls, E.D. (2016). Ambivalent aspirationalism in millennial postfeminist culture on Gossip Girl. Communication and Critical/Cultural Studies, 13(2), 198-213. 
Sarikakis, K., Krug, C., \& Rodriguez-Amat, J.R. (2017). Defining authorship in user-generated content: Copyright struggles in the Game of Thrones. New Media \& Society, 19(4), 542-559.

Scaraboto, D., \& Fischer, E. (2013). Frustrated fatshionistas: An institutional theory perspective on consumer quests for greater choice in mainstream markets. Journal of Consumer Research, 39(6), 1234-1257.

Spanò, C. (2016). Audience engagement with multi-level fictional universes: The case of Game of Thrones and its Italian fans. Journal of Audience \& Reception Studies, 13(1), 625-655.

Stebbins, R.A. (2017). The sociology of entertainment: A reference handbook. In C.D. Bryant, \& P. D.L. (Eds.), 21st Century Sociology. London: Sage.

Steiner, T. (2015). Steering the author discourse: The construction of authorship in quality TV, and the case of game of thrones. Series - International Journal of TV Serial Narratives, 1(2), 181-192.

Suarez, M.C., \& Erbisti, M. (2019). Ad Blocking: Discursos de Adoção e de Anticonsumo da Publicidade. RAE, 59, 170-182.

Thompson, C.J., Arnould, E., \& Giesler, M. (2013). Discursivity, difference, and disruption: Genealogical reflections on the consumer culture theory heteroglossia. Marketing Theory, 13(2), 149-174.

Young, H. (2014). Race in online fantasy fandom: Whiteness on Westeros. Org. Continuum, 28(5), 737-747.

Zajc, M. (2015). Social media, prosumption, and dispositives: New mechanisms of the construction of subjectivity. Journal of Consumer Culture, 15(1), 28-47.

Zanette, M.C., \& Brito, E.P.Z. (2019). Fashionable subjects and complicity resistance: Power, subjectification, and bounded resistance in the context of plus-size consumers. Consumption Markets \& Culture, 22(4), 363-382.

\section{Corresponding author}

André Luiz Maranhão de Souza-Leão can be contacted at: andre.sleao@ufpe.br
Resisting to

Game of

Thrones

Associate Editor: Sofia Ferraz

For instructions on how to order reprints of this article, please visit our website:

www.emeraldgrouppublishing.com/licensing/reprints.htm

Or contact us for further details: permissions@emeraldinsight.com 